\title{
Editorial
}

\section{A Time to Reflect and a Look to the Future}

This time of year we often take time to celebrate the work of chironomid workers that have retired from their positions or passed on over the course of the past year. While we are still, of course, taking time to celebrate these individuals in this year's issue, we thought it might also be appropriate to take time to look to the future, and think about how we are able to inspire a new generation of chironomid enthusiasts.

Before reading further, take a moment to reflect upon how you first became interested in midges. Many of us can probably identify a key person or experience (or perhaps a series of people and/or experiences) that helped to form our career paths and research passions. For example, in last year's issue of CHIRONOMUS, Carlos de la Rosa shared his story of how Bill Coffman first inspired him to pursue chironomid research (de la Rosa 2015).

As for me, a series of events and individuals helped me to find my path. My interest in aquatic ecology began early on when I was required to complete a science fair project as a middle school student. As a kid that loved to get her hands dirty and feet wet and the daughter of an active wildlife biologist, doing a project that involved something outside was a logical way to go. I remember thumbing through books until I found a section highlighting pictures of bugs that lived under the water - I was intrigued. Somehow, under the direction of two fantastic science teachers at the middle and high school levels, this first simple project turned into a five-year series of aquatic ecology/biomonitoring-themed science projects that took me to national and international fairs, getting me hooked on research; importantly, I was also able to easily identify chironomids (albeit to the family level!). While I continued to stay engaged in research activities as I embarked on my undergraduate degree program at St. Olaf College, my path deviated from the world of aquatic insects - instead, I worked for a couple years with a professor who had strong interests in Ornithology, which I also found to be fascinating. During my senior year, though, I had the opportunity to enroll in a limnology course with aquatic ecologist Dr. Mike Swift, who re-invigorating my interest in aquatic insects. Later that same year, I took a winter ecology course with Dr. Charles Umbanhower - I keenly remember one lab activity where we walked along the banks of the Mississippi River's headwaters searching the snow for winter-emerging chironomids. Looking back, I'm not sure which is more memorable - finding an insect that could withstand cold temperatures and walk on snow-covered stream banks, or watching one of my classmates fill her waders by taking a tumble into the cold winter waters!

At this point, I was sold on advancing my research career, but was yet unsure of the specific direction, as I had keen interests in both birds and bugs. After talking with a few potential major advisors, I was encouraged to talk with Dr. Len Ferrington, at the University of Minnesota. We formed a connection almost immediately - not only did his lab pursue research questions related to aquatic ecology and environmental change, but importantly for me, working in his lab would provide an opportunity to further explore my interests in the biology and ecology of those winter-emerging flies I became fascinated with the year before (fortunately for me, only once during my four seasons of winter work as a graduate student did I fill my waders!). Working with Len turned out to be a great fit - I was urged to explore my own interests, but also encouraged to step outside of my comfort zone and take on new challenges and opportunities. One of these involved pursuing a Fulbright Scholarship that allowed me to spend a year working with and learning from Drs. Torbjørn Ekrem and Elisabeth Stur at the Norwegian University of Science and Technology. This experience pushed me to further broaden my interest and experience with chironomids, shifting from studies with a primarily ecological focus to those based on chironomid taxonomy and systematics. As it turned out, this work turned out to be the component of my dissertation that I am proudest of, as it was an area I initially had limited knowledge and interest in, but one in which I ended up developing a very strong passion.

While my professional career is arguably still in its infancy as compared to many of you, all of these people (among many others!) and experiences played a key role in forming who I am as a researcher and an educator. The foundations and encouragement these individuals provided me with was absolutely infectious - being able to pass on an enthusiasm for research and continual learning was one of primary reasons I chose to pursue a career in higher education, particularly at a primarily undergraduate institution where I, too, can stimulate the next generation of researchers. While my time in the research lab is now quite limited because of teaching obligations, being able to kindle a keen passion for research in at least a couple of students per year who have strong potential is certainly worth it. 
Since starting my faculty position at Northern State University four years ago, I've had the opportunity to work with three exceptional students, each of whom has pursued a fairly significant research project involving chironomids. Their stories are highlighted later in this issue (Anderson et al. 2016). While they may or may not continue to study chironomids as they find their future paths, they have, at minimum, gained a stronger grasp and interest in research and will undoubtedly look back fondly on what they gained via their time studying chironomids. Whenever given the chance, I'd encourage all of you to take an interested young student under your wing and share your passion with them, even if this involves only a brief but enthusiastic conversation. It does make a difference, and you never know, you may be inspiring one of the next prominent chironomid enthusiasts!

Alyssa M. Anderson

Department of Biology, Chemistry, Physics, and Mathematics, Northern State University, Aberdeen, South Dakota, USA.E-mail:alyssa.m.anderson@northern.edu

\section{References:}

Anderson, A.M., Roberts, N.J., Durnin, T.I. and Wollman, K.M. 2016. Benefits of chironomid research: Perspectives from undergraduate researchers. - Chironomus Journal of Chironomidae Research. DOI: http://dx.doi.org/10.5324/cjer.v0i29.2179

de la Rosa, C. L. 2015. Chironomids: A Personal Journey. - Chironomus Journal of Chironomidae Research. 28: 30-35. DOI: http://dx.doi.org/10.5324/cjer.v0i28.1876 